\title{
Digitization of Transport Service in Pakistan: A Consumer Perspective
}

\author{
Iqbal Yasin ${ }^{1}$ and Malik Abdul Naveed Awan ${ }^{2}$ \\ ${ }^{1}$ Faculty of Business Administration, IQRA University, Islamabad, Pakistan, \\ ${ }^{2}$ Faculty of Business, The Millenium University College, Islamabad, Pakistan
}

\begin{abstract}
The purpose of this study is to understand role of peer-to-peer fee based taxi service for women in developing economy. This research provides insight into the importance of shared economy and collaborative consumption for growth of society and women empowerment through digitalized services. Four focus group discussions were conducted with each comprising at least seven participants to explore the issue. Only women were taken as sample of consumers in this study, as in low income and collectivist societies women are not considered active part of economy. Therefore perception of women regarding such digitalized services is important to be understood. Results indicate that the women feel more empowered and are an active member of society now. Peerto-peer based taxi service enables women to participate in market with ease to acquire low cost services which are secure due to tracking system. Encouraging women to be part of the transport system as suppliers will be bigger contributing factor in low income economies such as those of Pakistan.
\end{abstract}

Keywords: Collaborative Consumption, Consumer Perspective, Uber, Careem

\section{INTRODUCTION}

The advent of technology has changed many business frontiers in no time and has helped in developing platforms that can support collaborative consumption and adoption of sharing economy. Sharing economy collectively is a peer-to-peer economic model of acquiring, providing or sharing access to goods and services [1] mostly facilitated by a community based on-line platform. Uber is one of such service provider where it aggregates individual's transport resource and helps them sharing it with others. According to Brookings India report [2] private vehicles go unused for $95 \%$ of their lifetime which could be used to reduce the overburdened public transport specially in mass populated regions such as India and Pakistan. Enabled digitization of services has helped individuals to focus on such opportunities where their physical property can be utilized by others and can provide owner with additional financial benefit.

Penetration of peer-to-peer fee based ride sharing services is facilitated by factors including: information \& communication technology (ICT) growth and supply side flexibility. ICT growth has enabled different segments including suppliers, customers and aggregators (platforms that combine different segments on single platform) to communicate and share resources easily. It has also eased entry of suppliers with marginable gains, facilitated customers with real time resource searching capability and provided secure financial options with much lower transaction cost. Supply side flexibility reflects the removal of market entry and exit barriers. For instance supplier in Uber or Careem (Middle Eastern company operating in Pakistan) can join in or opt out with just a few clicks. Such flexible entry and exit options have allowed individuals from all professions to join in and share resource, hence increasing availability of online suppliers.

On the other hand it also provided opportunity to customers to get faster and cheaper access to transportation resource. Such collaborative consumption orientation is shifting consumers' consumption patterns especially due to digitized services. Digitization of services and customers' increased online connectivity has made collaborative consumption more effective and applicable. However, in collective societies, where sharing resources is considered important, people do not promote paid sharing. As they believe that sharing among close circles is one's duty. In Pakistan, a highly ranked collectivist society, Uber is considered successful venture and is now facing fierce competition from Careem; a Middle Eastern company operating in Pakistan.

Corresponding Author: Iqbal Yasin, Faculty of Business Administration, IQRA University, Islamabad, Pakistan, iqbal.yasin@iqraisb.edu.pk 
Similarly, Pakistan is ranked low in indulgence with score as low as zero. Indulgence means the desire people have to control their desires and impulses [3]. In such society, free movement of women is not easy leading them to avoid active involvement in economic and social activities, including jobs, education and purchasing. A common issue raised in society is women have to be accompanied with a man from close family, which hinders the free movement of women. However, app based taxi services (Uber, Careem etc) have reduced this issue to some extent. It is now much easier to get a taxi service at home. However, potential benefits of peetto- peer fee based services are important to be understood for better maximum gain from these services. Therefore, this study explores the potential benefits, challenges, reasons to acquire such services by women in Pakistan.

\section{LITERATURE REVIEW}

Uber's marketing strategy in India, a neighboring country to Pakistan, has been unconventional. By charging lower rates to the passengers and by paying a hefty share of the ride payment to the drivers, Uber wanted to be in the news, create hype, and generate a trial. Uber believed that once the customers tried their service, they will come back- and they did.

The recent problems related to Careem in Pakistan are about its surcharge at peak times. The surcharge at peak times can be very high. Surcharge, by Careem's definition, is called 'the peak factor' in Pakistan. The peak factor has caused criticism of Careem in Pakistan by its users.

However, the peak factor charges are not hidden charges taken from the customer. Rainy days, festivals, weekends, daily peak hours all lead to the payment of the peak factor or a surcharge. Surcharges on special occasions get even higher. Careem in Pakistan, for example, charged really high fares to the customers who were certainly not happy about it [4].

The Careem users in Pakistan are also displeased as some months ago, in April 2017, they stood for the company morally when the government decided to regulate the service. The customers were against any regulation on this service. With that stand, the customers now feel betrayed with the peak factor rates and surcharge, and are asking the government to regulate such taxi services and to take action against the companies.

However, Careem's Managing Director, Junaid Iqbal, questions that on festivals such as Eid, how else do you convince a captain (driver) to take a ride other than incentivizing him really well? Careem drivers (called captains) are independent contractors, similar to Uber drivers. Uber drivers get to keep around 80 percent of the total payment charged to the customer. Hence, the monetary incentives are encouraging more educated people to try the Uber venture as drivers. The Uber model has been praised as benefiting both the business organization and sufficiently compensating the drivers.

The drivers are rated by the passengers on a score at the end of a trip through the smartphone application. Hence, the drivers have an incentive to provide a good service, for example, to greet the passengers, to offer them water and candy. Plus, it has been observed on social media that the users of Uber and Careem post about the good drivers and their riding experiences with them. The company (Uber) tends to drop its drivers who have low scores. Hence, maintaining a cordial relationship with each passenger is important for the driver for a healthy work routine and for stable employment.

Some factors make services such as Uber and Careem stand out and win customers over the conventional cab drivers. Firstly, Uber and Careem can charge (and change) prices based on customer demand and traffic, as opposed to the standard taxis which have a central authority to overlook their pricing strategies. As for Uber and Careem in Pakistan, there is currently no regulation on their trip prices. The customers on their part have to agree to the price before riding as all details are shared with them through the smartphone application. Hence, there is no hidden

charge or bluffing the customers in that regard. Secondly, as for the companies' strategies, both discounts and surcharges are well planned. Some authors point to an innovative pricing strategy adopted by Uber [5]. Moreover, the concept of cleaner cars, a verified driver, and bigger discounts at certain times all add up to getting the share of the customer for Uber and Careem from the conventional cab service in Pakistan.

The opportunity for Uber in India can be gauged by the fact that Uber India is the largest market for the company outside the United States. With increased smartphone penetration in India and Pakistan, innovative practices, and increased urbanization, organized cab services are expected to expand their businesses and profits. The rural-urban migration in this part of the world, presence of an energetic young population that is enrolling in higher education, and limited public transportation options all contribute to growing demand for organized cab service.

The organized cab service in this part of the world (South Asia) has not been without problems. The going has been tough for Uber in India. There has been fierce competition and the company has met 
legal complications. Uber has been at odds with authorities in India. In New Delhi, the capital, the government banned its services after an Uber driver was accused of some crime. But a court revoked the ban later. After some security incidents, Uber has tightened its driver screening in India and also tightened its in-app safety features. Plus, there have been reports of sexual harassment of passengers in India. In Pakistan also, there have been reports of crime on social media by different users of Uber in Pakistan while availing the ride service.

However, many of the claims go unverified. A report from Bangladesh points to similar sexual behavior of taxi drivers, especially those who have migrated from rural to urban Bangladesh. The situation, therefore, can be alarming.

Furthermore, contractor strikes by Uber and Ola are not uncommon in India. This is due to frequent policy changes by cab services and similar strikes have been observed by Uber and Careem drivers in Pakistan. Another disturbing phenomenon for Uber in India has been Praveen Kumar's suicide, the first Uber driver in India to commit suicide.

According to Junaid Iqbal, the Managing Director (MD) of Careem, drivers present fake licenses in the hope of becoming contractors for the company. Hence, the company has become more vigilant in its driver (captain) selection. Secondly, the needy rickshaw and taxi drivers will suffer as more people, at least in the urban areas, start switching to organized cab which can be available at their doorstep. Moreover, since the ownership of this mode of transportation is in private hands, there may be pressure on government authorities to keep a check on the practices of organized cab service and to regulate them. This is more likely if the number of customer complaints of exploitation increase.

\section{METHODOLOGY}

Our findings are based on focus group discussion conducted in four sessions. Focus group offers exemplary benefits as compared to in-depth interviews with the first one being it is a costeffective method in terms of saving time, money, and resources. In addition, the researcher gets firsthand knowledge on key issues surrounding his/her topic with respondents' quick feedback.

Focus groups facilitate to get in-depth information on respondents' beliefs, choices, feelings, thoughts and behaviors [6]. In addition, focus groups can generate large amounts of data in a relatively short time span. Focus group is often used for respondents to open up freely and share information comfortably whereas for others it requires trust and effort [7].

Participants for focus groups were chosen carefully with special attention that no one knew each other as it allows them to share more openly. Participants' profile is provided below as per focus groups conducted. Table 1 below on the next page shows first set of participants, all of them were professionals with annual income over USD 10000.

Table 1: Participant details for focus group 1

\begin{tabular}{llll}
\hline Focus Group 1 & & & \\
\hline Participant & Age & Occupation & Annual Income \\
Participant No 1 & 32 & Private University Teacher & 15000 USD \\
Participant No 2 & 28 & Front Desk Officer (Bank) & 10000 USD \\
Participant No 3 & 31 & Database Administrator & 13000 USD \\
Participant No 4 & 32 & Public University Teacher & 12500 USD \\
Participant No 5 & 37 & Assistant Manager (Bank) & 17000 USD \\
Participant No 6 & 43 & Marketing Manager (Telecom) & 19000 USD \\
Participant No 7 & 35 & Private University Teacher & 15000 USD \\
Participant No 8 & 39 & Public Office Holder & 19000 USD \\
Participant No 9 & 34 & Public University Teacher & 15000 USD \\
\hline Focus Group 2 & & & \\
\hline Participant & Age & Occupation & Annual Family \\
& & & Income \\
Participant No 1 & 24 & MS Student & 10000 USD
\end{tabular}




\begin{tabular}{|c|c|c|c|}
\hline Participant No 2 & 25 & MS Student & 8000 USD \\
\hline Participant No 3 & 23 & MS Student & 9000 USD \\
\hline Participant No 4 & 30 & MS Student & 10000 USD \\
\hline Participant No 5 & 26 & MS Student & 8000 USD \\
\hline Participant No 6 & 24 & MS Student & 11000 USD \\
\hline Participant No 7 & 25 & MS Student & 9000 USD \\
\hline Participant No 8 & 27 & PhD Scholar & 9500 USD \\
\hline Participant No 9 & 29 & PhD Scholar & 12000 USD \\
\hline \multicolumn{4}{|l|}{ Focus Group 3} \\
\hline Participant & Age & Occupation & Annual Income \\
\hline Participant No 1 & 30 & Research Associate & 9000 USD \\
\hline Participant No 2 & 27 & Network Engineer & 8700 USD \\
\hline Participant No 3 & 29 & Business Development Officer & 7000 USD \\
\hline Participant No 4 & 27 & Accountant & 8500 USD \\
\hline Participant No 5 & 32 & Customer Services Officer & 9000 USD \\
\hline Participant No 6 & 31 & Research Coordinator & 6000 USD \\
\hline Participant No 7 & 28 & Program Manager & 8000 USD \\
\hline Participant No 8 & 49 & Programmer & 9500 USD \\
\hline Focus Group 4 & \multicolumn{2}{|r|}{+2} & \\
\hline Participant & Age & Occupation & Annual Income \\
\hline Participant No 1 & 37 & Architect & 13000 USD \\
\hline Participant No 2 & 43 & Doctor & 17000 USD \\
\hline Participant No 3 & 29 & House Wife & 10000 USD \\
\hline Participant No 4 & 34 & Public University Teacher & 11500 USD \\
\hline Participant No 5 & 37 & $\mathrm{PhD}$ Scholar & 5000 USD \\
\hline Participant No 6 & 28 & Front Desk Officer & 6000 USD \\
\hline Participant No 7 & 42 & Manager & 15000 USD \\
\hline
\end{tabular}

After detailed discussions with focus groups, thematic analysis was done to take out important points in the discussion. Conversation was recorded and later on themes were generated. Results are presented in the next session.

\section{RESULT, ANALYSES AND DISCUSSIONS}

The findings of our study point out to the importance of digitalization in the context of developing markets where digitalization is setting in rapidly. The female informants of our study have revealed at length how the digitalization of the transport service is changing their lives. Firstly, in the context of Pakistan, a traditionally conservative society, women were seen in traditional and household roles. According to the informants of our study, the ride sharing services such as Uber and Careem have empowered them as they feel themselves as more mobile now.

The services of Uber and Careem are compared by our informants based on the convenience that the smart phone application provides. Careem was rated as more user friendly, compelling more customers to use the service when compared with Uber. A most interesting finding of our study is that services based on digitalization, such as Uber and Careem, are changing social norms. For example, a few informants elaborated that we were generally not allowed to travel outside the house alone or with strangers to reach our destination, be it a university or a corporate office. The ride sharing applications and services, and particularly Careem in the local context, are changing societal norms and letting family members conveniently allow females to travel with total strangers.

This has been made possible, according to the informants, by the trust that Careem has created with its security features. For example, the Careem Captains are carefully selected and their previous record with the police station is also verified to ensure that the Captains have a clean past record where their public dealing is concerned. Moreover, the digitalization has made it easier for the ride sharing applications to enable the users to 'share' their location with family as they travel. Hence, the whole journey with a Careem or Uber captain can be monitored by a family member or friend. A societal barrier, of not allowing women to travel alone, has been broken in such developing economies by the trust created by services such as Careem and Uber while they were competing with conventional cab service.

Interestingly, the informants of our study believe that their consumption in the society has increased after the advent of such ride sharing services. This is because the women are able to travel more freely, even at odd times, to go as consumers to different places. Moreover, they also feel of themselves now as better contributors to society and to economic output. Our respondents equally believe that Careem and Uber have given them more autonomy in life. A 
digitalized economy is helping the women to prosper and contribute more to the economy.

However, such digitalization in the economy is not without problems. A few of the respondents have previously felt harassed while riding with such services, and Uber has been notorious in this context. Most of the harassment cases that our informants discussed related to Uber in the context of Pakistan as opposed to Careem. One reason that was pointed out is the increased scrutiny by Careem when selecting their captains. As one respondent explained, "I was never allowed to travel alone in a taxi; I had to be accompanied by my brother or father. But the trend has changed now; my family knows where I am and which captain I am with, so they allow me to go where I want" (Focus Group 2, Respondent 7).

Technological advancement through these applications and services is providing convenience and cheap prices to our respondents. Since we had a diversified respondent group for the purposes of this study, the variations in the responses provided interesting insights. For example, for one respondent, the preference for choosing a ride was not the price but the behavior of the captain, how quickly he reached the destination, and whether he engaged in a personal level conversation with the passenger.

Importantly, one informant said that female captains are now a part of Careem service and the informant had a great riding experience with one female captain. This again goes on to show the changing societal values due to digitalization in the economy; the process is making women a greater part of the workforce and helping them contribute productively to the economy. However, some respondents see the presence of female captains as a problem due to the conservative nature of the society and believe that female captains shall be bullied by the customers.

The results of our study also point out to challenges that digitalization of services and the economy has caused. Three informants of our study have witnessed that the captains are not well trained in using the smartphone application of Uber and Careem to be able to navigate and reach the destination with any trouble. Many times, the captains ask the riders for guidance on how to use the application properly on their smartphones. There is also an issue of GPS tracking in the services of Uber and Careem, where the applications show false results and destinations and not the exact location of the rider when he/she needs to be picked up. One informant was willing to share a solution: "Careem captains do go through trainings by their headquarters; however, I feel that such trainings are elementary for the drivers. Firstly, they do not know how to use the application, and secondly, they also do not know how to talk to the customers" (Focus Group 3, Respondent 2).

The success of such applications and services in the context of Pakistan, as in many other countries, is based on the rating system. Captains are many times given a good rating by the customer out of sympathy. One informant said: "I do not wish for the poor captain to lose his job, so I give the innocent soul a good rating" (Focus Group 3, Respondent 6). Hence, the rating system itself appears superficial and flawed as in a collectivist culture, people are working for the benefits of others and do not want to cause them any harm.

\section{Discussion}

The issue of privacy was discussed at length by our respondents. While a reality in most economies is that people's personal lives and contact details are more exposed with digitalization, most of our informants were not worried about this trend. One respondent argued, "We are already sharing so much of our information through social media platforms; what difference does it make if we now share such information with Careem and Uber?" (Focus Group 1, Respondent 1)

As part of the discussion section, we will be comparing the findings of the study with the available literature. Our study points out that those females who were out of a running economy now find a place in the market as consumers and as important contributors to the economy.

Consumption has increased due to the female gender who are a large part of Pakistan's economy. Women feel empowered with such digitalization of services and markets and feel that they are in control of their lives. The literature, on the other hand says that privacy issues are of prime importance to consumers while these location-based apps provide various benefits [8]. However, our study did not find the consumers to worry about privacy concerns as they share their personal information with these companies and are at ease. This represents a changing mindset in a conservative society. Privacy was not identified as the most important issue or concern related to location-based applications.

Secondly, a study in the context of India, a neighboring country to Pakistan, highlights that ride sharing applications and services are trying to be more creative in offering promotions and benefits to the consumers. However, the Indians just want discounts and are not concerned with any other benefits or promotions [9]. Our particular study did identify factors which were more important to the consumers other than price. For example, a safe and 
comfortable journey was rated as more important than prices by most of our informants. This is an interesting finding in the context of India and Pakistan and their region as there have been previous studies talking about the price consciousness of consumers in this part of the world as of prime importance.

Moreover, while our study was not able to collect latest statistics related to the ride sharing applications, it was found through the focus group discussions that consumers enjoyed regular promotions and incentives (including the "promo codes') offered by Careem when compared with no such incentives or benefits with traditional cab services. Our findings support the literature which states that, in the context of India, the conventional taxi drivers may become irrelevant due to the large success and connectivity of services such as Ola and Uber [10].

\section{CONCLUSIONS}

As part of the conclusion, it must be pointed out that one limitation of our study is that the perspective of only the female gender has been taken.

Secondly, the study has purely been based on the consumer segment; the opinions of the captains have not been a part of this study.

It is recommended that the companies should work on the attitude and behavior of the captains for sustained benefits to the company and for consumer loyalty. Moreover, extensive training, and especially technical training, needs to be provided to the captains so that they are able to effectively use the smart phone application. The navigation service of Uber needs to improve in Pakistan as the locations are many times not accurate. A larger and a better fleet of cars shall attract more consumers to this service as 'comfortable ride' was a major feature of the respondents' answers. More importantly, the customers need to be made more autonomous and vocal. This will come through the important features of rating and bookings. For example, while rating a captain, there should be an option of posting comments about the captain for the benefit of next riders. The comments section should also be enabled for the consumer while booking a ride so that any specific requirements and details can be shared by the passenger in due time.

Future studies are suggested to authors, firstly, to confirm the results of our study. The results may be confirmed with follow up quantitative studies. Secondly, the perspective of captains should be taken to explore the topic further.

\section{REFERENCES}

[1] ZERVAS, G.,PROSERPIO,D.\&BYERS, J.W. 2014. The rise of the sharing economy: Estimating theimpact of Airbnb on the hotel industry. Journal of Marketing Research.

[2] YARAGHI, N. \& RAVI, S. 2017. The current and future state of the sharing economy.

[3] HOFSTEDE, G. 2010. Geert hofstede. National cultural dimensions.

[4] BAIG, M. H. 2017. Post-Eid peak factor : CAREEM ripping off Pakistanis. [Online]. Available: https://www.telenews.pk/2017/07/05/post-eidpeak-factor-careem-ripping-off-pakistanis/ [Accessed 9th July2017].

[5] MOHAMMAD, R. 2013. Uber's “price gouging" is the future of business. Harvard Business Review. Retrieved from https://hbr. org/2013/12/ubers-price-gouging-is-thefuture-of-business.

[6] HESSE-BIBER, S. N. \& LEAVY, P. 2006. Emergent methods in social research, Sage.

[7] RABIEE, F. 2004. Focus-group interview and data analysis. Proceedings of the nutrition society, 63, 655-660.

[8] YUN, H., HAN, D. \& LEE, C. C. 2013. Understanding the use of location-based service applications: do privacy concerns matter? Journal of Electronic Commerce Research, 14, 215.

[9] MURALIDHAR, S.H. 2016. How OlaDisrupted TaxiServices in India? Review of Knowledge Management, 6, 5.

[10] SURIE, A. \& KODUGANTI, J. 2016. The Emerging Nature of Work in Platform Economy Companies in Bengaluru, India: The Case of Uber and Ola Cab Drivers. EJournal of International and Comparative Labour Studies, 5. 